\title{
Solar/lamp-irradiated tubular photoreactor for air treatment with transparent supported photocatalysts
}

\author{
R. Portela ${ }^{a}$, S. Suárez ${ }^{a}$, R.F.Tessinari ${ }^{a b}$, M.D. Hernández-Alonso ${ }^{a}$, M.C. Canela ${ }^{b}$, B. Sánchez ${ }^{a}$ \\ ${ }^{a}$ CIEMAT-PSA-Environmental Applications of Solar Radiation. Madrid, Spain. \\ ${ }^{b}$ UENF-CCT-Chemical Sciences Laboratory. Campos dos Goytacazes-RJ, Brazil. \\ contact e-mail: raquel.portela@ciemat.es
}

\section{ABSTRACT}

A novel versatile tubular reactor that may use both types of radiation, solar and/or artificial, and different types of suspended or immobilized photocatalysts is proposed. The photocatalytic reactor was evaluated for air treatment at laboratory scale and semi-pilot-plant scale. UV-A transparent immobilized photocatalysts were employed, which allowed an efficient use of radiation. Two different types of photocatalytic modules were tested: a) $\mathrm{TiO}_{2}$-coated PET monoliths and b) $\mathrm{TiO}_{2}$-coated glass slides, arranged in monolith-like units with the help of especially designed star-shaped polygonal structures. Both types of units were easy to handle and assured the adequate distribution of the photocatalyst inside the tubular reactor. The efficiency of the photocatalytic system with both solar and artificial radiation to oxidize the $\mathrm{H}_{2} \mathrm{~S}$ contained in an air stream was demonstrated at the laboratory roof and in the treatment of real air of a wastewater treatment plant located in Madrid (Spain). As a consequence of the chemical nature of the pollutant, the photocatalytic activity decayed over time due to the accumulation of sulfate on the surface, but easy regeneration of the exhausted photocatalyst was achieved by washing with water.

KEYWORDS: Photoreactor, pilot-plant, solar, UV-lamp, supported photocatalyst, monolith, $\mathrm{H}_{2} \mathrm{~S}$

\section{INTRODUCTION}

In gas phase heterogeneous photocatalysis, the advantages of working with immobilized instead of suspended catalysts are clear. These include no need for fluidization -the fluidization would entail reduced operational flexibility and difficulty in the scaling-up- and easy recovery and reuse of the catalyst, avoiding a separation stage after treatment. Due to the small particle size of $\mathrm{TiO}_{2}$, a conventional sedimentation process would require high residence times; hence more complex and expensive separation systems would be necessary, such as sedimentation accelerated by coagulation [1], magnetic separation [2] or membrane filtration [3]. There are, however, some disadvantages of working with immobilized photocatalysts that must be overcome: decreased activated surface per unit mass -compared with the catalyst in suspension-; reduced catalyst mass to fluid volume ratio; mass transfer limitations at low flow rates and difficulty in achieving efficient irradiation of the entire photocatalyst surface without casting shadows, especially in the case of solar radiation. Therefore, most photocatalytic 
reactors are designed for liquid phase and employ photocatalysts in suspension. For these applications tubular reactors are usually selected. These systems can operate with adequate flow regimes and greater quantum yield may be obtained, since practically all the radiation affects the reaction medium. Moreover, the radiation source may be either artificial surrounding the reactor [4] or placed in the reactor axis [5]- or the sun, and the reactor may be placed in the focus of reflectors that collect the radiation efficiently [6]. Non concentrating Compound Parabolic Collectors (CPCs) have been widely used for photocatalytic water treatment applications [7-9] because all the incident radiation on the aperture area, diffuse radiation included, is directed to the reactor without a significant temperature increase and no tracking system is required.

Until the first solar pilot plants for polluted water treatment were constructed in the late $80 \mathrm{~s}$ at the National Renewable Energy Laboratory (NREL) and the Sandia National Laboratories (USA), photoreactor designs were not optimized for photocatalytic processes. Since then, different concepts have been proposed with a variety of designs, in an effort to increase efficiency and reduce costs [10]. The first solar photocatalysis industrial pilot-plant was installed in 1999 in Arganda del Rey (Madrid, Spain) for the treatment of non-biodegradable chlorinated hydrocarbon solvents [8]. However, water treatment by photocatalysis is not competitive with other technologies -such as biological treatment or photo-Fenton [11, 12]- and recent efforts in applied research of this technology are increasingly focused on the treatment of air [13-15].

There have been several attempts to use fluidized reactors for air treatment [16-18]. However, due to the advantages already mentioned, the vast majority of gas phase photoreactors are fixed or packed bed, where catalyst, irradiation and flow requirements strongly condition the system design and performance. This characteristic makes it difficult to find an optimal configuration, versatile and readily scalable. Despite the large number of laboratory-scale studies with different configurations found in the literature [19], there are relatively few studies at pilot scale or working in real conditions [20, 21] and almost none using solar radiation [22, 23]. Only previous works of the authors have explored the use of solar CPC for air treatment [24, 25]. Most effort is made in the development of prototypes of individual air purifiers, comprising filters with three-dimensional porous structures or a panel, containing or impregnated with $\mathrm{TiO}_{2}$ and illuminated by fluorescent UV lamps [21]. Monolithic structures are preferred, because they have a high surface area per unit volume and, in turn, low pressure drop, which has made them popular in thermal catalysis applications as well [26]. However, monoliths are often made of metal [15, 27], ceramic [28] or activated carbon [29] and therefore opaque. The penetration of light inside the monolith channels is very short [30], which requires for photocatalysis applications modular configurations consisting of shallow monoliths irradiated by groups of lamps located between them [31] or internally illuminated by optical fibers [32]. 
Some authors have used tubular reactors with supported photocatalysts, for example immobilizing the catalyst on the reactor walls in annular [33] or multi-annular [34] reactors or on randomly packed borosilicate glass rings [4, 35] or using tubular photocatalysts [36]. Nevertheless, in order to obtain reaction systems where the catalyst can be easily replaced, with good photon efficiency, high contact surface and low pressure drop, transparent monolithic supports are desirable. The approaches tried by the authors have been the use of coated borosilicate glass rings, ordered to form parallel channels to reduce pressure drop [37], and the use of polymeric monoliths of poly(ethylene terephthalate) (PET) and cellulose acetate [5, 38], which are inexpensive and lightweight alternatives to borosilicate glass.

In this research work, a new versatile tubular reactor, able to use both types of radiation, solar and/or artificial, and different types of supported photocatalysts, is proposed. The photocatalytic reactor was evaluated with two types of transparent supports, based on PET monoliths and modules of glass slides, for gaseous $\mathrm{H}_{2} \mathrm{~S}$ elimination both at laboratory and pilot-plant scale.

\section{EXPERIMENTAL}

\subsection{Photoreactor}

The tubular photoreactor designed comprises two concentric borosilicate glass tubes and the photocatalyst fills the space in-between $\left(D_{\text {ext }}=84 \mathrm{~mm}, D_{\text {int }}=32 \mathrm{~mm}\right)$. The reactor was placed in the roof of building 42 of Ciemat (Madrid, Spain), fixed in a platform tilted $40^{\circ}$-the local latitudeand facing south. The sun was employed as external radiation source, complemented by an artificial radiation source (CLEO Effect $70 \mathrm{~W}$ SLV, $\lambda_{\max }=350 \mathrm{~nm}$, Philips, started by electronic ballast ELXc170.205, Vossloh) placed inside the inner tube that allows for 24h operation in any climatic conditions. The radiation was reflected by a non-concentrating CPC with $L=1.25 \mathrm{~m}$ made of aluminum $4270 \mathrm{KKS} /$ Miro Sun (Alanod Aluminium $\mathrm{GmbH}$ ); this material ensures adequate optical performance and excellent optical durability [39]. Temperature sensors (K-type thermocouple) and calibrated UV-radiation sensors (G5842, Hamamatsu, 260-400 nm, peak sensitivity at $370 \mathrm{~nm}$ ) were placed on the CPC aperture plane to measure ambient temperature and incident solar irradiance. Additional sensors were introduced inside the reactor and fixed on the reactor walls in order to measure lamp irradiance -on the inner surface of the external tubeand solar irradiance -on the external surface of the internal tube-. An automated system was used to switch on or off the lamp depending on the incident radiation.

\subsection{Photocatalytic units}

Two different configurations, schematized in Figure 1, were studied. In both of them $\mathrm{TiO}_{2}$ was prepared by sol-gel and coated on the UV-transparent substrates to be used as photocatalyst. 


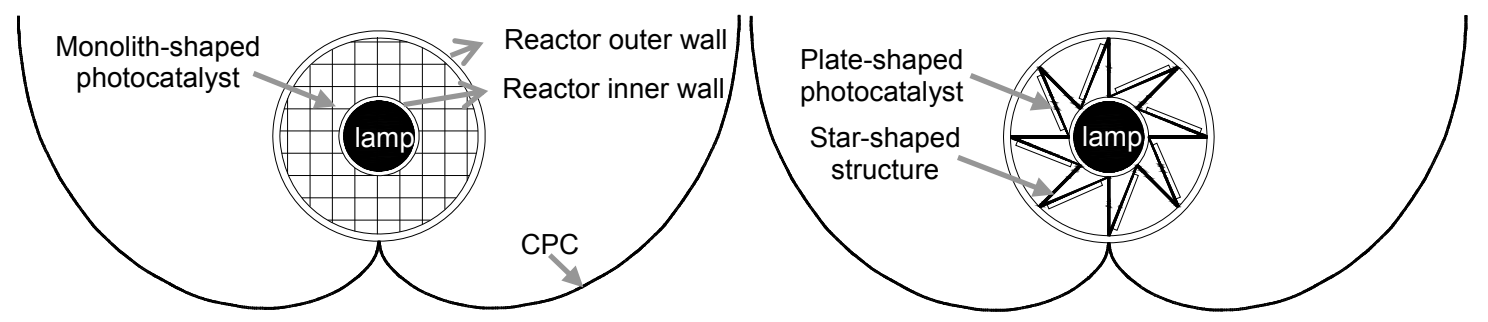

Figure 1. Scheme of the photocatalytic reactor:

A) The photocatalytic units are $\mathrm{TiO}_{2}$-coated PET monoliths.

B) The photocatalytic units are monolith-like structures composed of $\mathrm{TiO}_{2}$-coated glass plates.

In configuration $\mathrm{A}, \mathrm{TiO}_{2}$-coated $\mathrm{PET}$ monoliths ( $\mathrm{L}=70 \mathrm{~mm}, 9 \mathrm{~mm} \times 9 \mathrm{~mm}$ pitch cross-section) obtained from a commercial matrix (WaveCore PET150-9/S, wall thickness of $0.15 \mathrm{~mm}$, density of $45 \mathrm{Kg} / \mathrm{m}^{3}$, Wacotech $\mathrm{GmbH}$ ) were used as photocatalytic units. As previously described, an acid aqueous sol was prepared in order to obtain crystalline $\mathrm{TiO}_{2}$ without need of high temperature treatment [5]. Three $\mathrm{TiO}_{2}$ layers were deposited by dip-coating at a withdrawal rate of $1.5 \mathrm{~mm} \cdot \mathrm{s}^{-1}$ and dried at $50^{\circ} \mathrm{C}$, resulting in $65 \mathrm{mg} \mathrm{TiO} 2$ per monolith $\left(0.2 \mathrm{~g} \mathrm{TiO}_{2} \cdot \mathrm{L}^{-1}, 0.9 \mathrm{~g}\right.$ $\left.\mathrm{TiO}_{2} \cdot \mathrm{m}^{-1}\right)$.

The alternative configuration $\mathrm{B}$ allows the use of simple plate-shaped photocatalysts. $\mathrm{TiO}_{2}$ coated glass slides (26 mm x $76 \mathrm{~mm}$, Menzel-Gläser) were prepared following the same procedure used for the PET monoliths, but in this case the drying temperature was $100^{\circ} \mathrm{C}$, resulting in ca. $1.5 \mathrm{mg} \mathrm{TiO}_{2}$ per slide. In order to obtain an adequate distribution of the catalyst inside the reactor and make it easy to handle, the plate-shaped photocatalytic pieces were assembled to obtain three-dimensional channeled units by means of especially designed hollow structures in the form of a star-shaped concave polygon with 8-fold rotational symmetry [40]. Each unit was composed by 8 plates fixed by the narrow edges to two of the star-shaped structures. With this configuration the photoreactor contained $0.03 \mathrm{~g} \mathrm{TiO}_{2} \cdot \mathrm{L}^{-1}\left(0.16 \mathrm{~g} \mathrm{TiO}_{2} \cdot \mathrm{m}^{-1}\right)$.

\subsection{Photocatalytic activity}

In the laboratory tests, performed at the roof of building 42 (Ciemat), the reactor was fed with a gas stream at $50{ }^{\circ} \mathrm{C}$ composed by $\mathrm{H}_{2} \mathrm{~S}$-from a $\mathrm{N}_{2} / \mathrm{H}_{2} \mathrm{~S}$ gas cylinder (Air Liquide)- and zero air from an air compressor equipped with $\mathrm{CO}_{2}$ and moisture filters-. When needed, the gas stream was humidified with distilled water by means of a controlled evaporation and mixing system (CEM, Bronkhorst). The flow rates were adjusted with mass flow controllers to obtain the desired operational conditions. $\mathrm{H}_{2} \mathrm{~S}$ and $\mathrm{SO}_{2}$ (gaseous product) were measured by gas chromatography with a CP-4900 micro-GC (Varian). Hydrogen sulfide conversion values and selectivity to sulfur dioxide were calculated as follows: 
Conversion $(\%), \mathrm{X}_{\mathrm{H}_{2} \mathrm{~S}}=\frac{\left[\mathrm{H}_{2} \mathrm{~S}\right]_{\text {in }}-\left[\mathrm{H}_{2} \mathrm{~S}\right]_{\text {out }}}{\left[\mathrm{H}_{2} \mathrm{~S}\right]_{\text {in }}} \cdot 100$

Selectivity $(\%), \mathrm{S}_{\mathrm{SO}_{2}}=\frac{\left[\mathrm{SO}_{2}\right]_{\text {out }}}{\left[\mathrm{H}_{2} \mathrm{~S}\right]_{\text {in }}-\left[\mathrm{H}_{2} \mathrm{~S}\right]_{\text {out }}} \cdot 100$

In the Wastewater Treatment Plant (WWTP) pilot-plant test, the reactor was fed with air taken from the primary sludge sieve by means of a diaphragm vacuum pump ( $\mathrm{MZ} 2 \mathrm{C}$, Vacuubrand). The air flow entering the reactor was adjusted to $1 \mathrm{~L} \cdot \mathrm{min}^{-1}$ with a rotameter. $\mathrm{H}_{2} \mathrm{~S}$ and $\mathrm{SO}_{2}$ were monitored on-line with electrochemical sensors (Zareba Sensepoint, Honeywell Analytics) placed in the reactor inlet and outlet. Stainless steel tubes filled with Tenax TA as adsorbent and connected to sampling pumps (Gillian) were used in specific samplings performed to analyze other volatile organic compounds (VOCs) present in the air. The air passed through the tubes at $200 \mathrm{~mL} \cdot \mathrm{min}^{-1}$ during $4000 \mathrm{~s}$. The pollutants concentrated in the adsorbent were later desorbed and analyzed using an Automated Thermal Desorber (ATD-Turbo Matrix 650, PerkinElmer) connected to a GC-MS (5973/6850, Agilent). The collected compounds were identified using either a reference mass spectra library (NIST-02) or reference compounds.

\subsection{Photocatalyst regeneration}

Distilled water was used to wash twice the spent photocatalysts in $100 \mathrm{~mL}$ per glass plate. The water was then analyzed by ionic chromatography (sulfate) and inductively coupled plasma atomic emission spectroscopy (Ti).

\section{RESULTS AND DISCUSSION}

\subsection{Configuration A: PET monoliths}

The first tests with the new photocatalytic reactor were performed in the facilities of Ciemat under solar radiation in summer. Three PET monoliths ( $1 \mathrm{~L}$ reaction volume) were used to treat $1 \mathrm{~L} \cdot \mathrm{min}^{-1}$ dry air $\left(3.5 \cdot 10^{-3} \mathrm{~m} \cdot \mathrm{s}^{-1}\right.$ linear velocity). The system worked satisfactorily during the treatment of $15 \mathrm{ppm} \mathrm{H}_{2} \mathrm{~S}$ (Figure 2). Almost 100\% conversion was attained the first day of operation during the daytime; at night, since the lamp was not used, inlet and outlet concentration were exactly the same, as a consequence of the low adsorption capacity of the photocatalyst, which contains a low amount of $\mathrm{TiO}_{2}$. With the sunrise, the photocatalytic activity was recovered, although it was slightly lower with respect to the first day. Photocatalytic activity was observed between 8:00 and 21:00, approximately, reaching a maximum at around 15:00, corresponding to a UV-A irradiance on the inner tube of $7 \mathrm{~mW} \cdot \mathrm{cm}^{-2} \cdot \mathrm{SO}_{2}$ was released as gaseous by-product in increasing amounts, according to previous results [41]. 


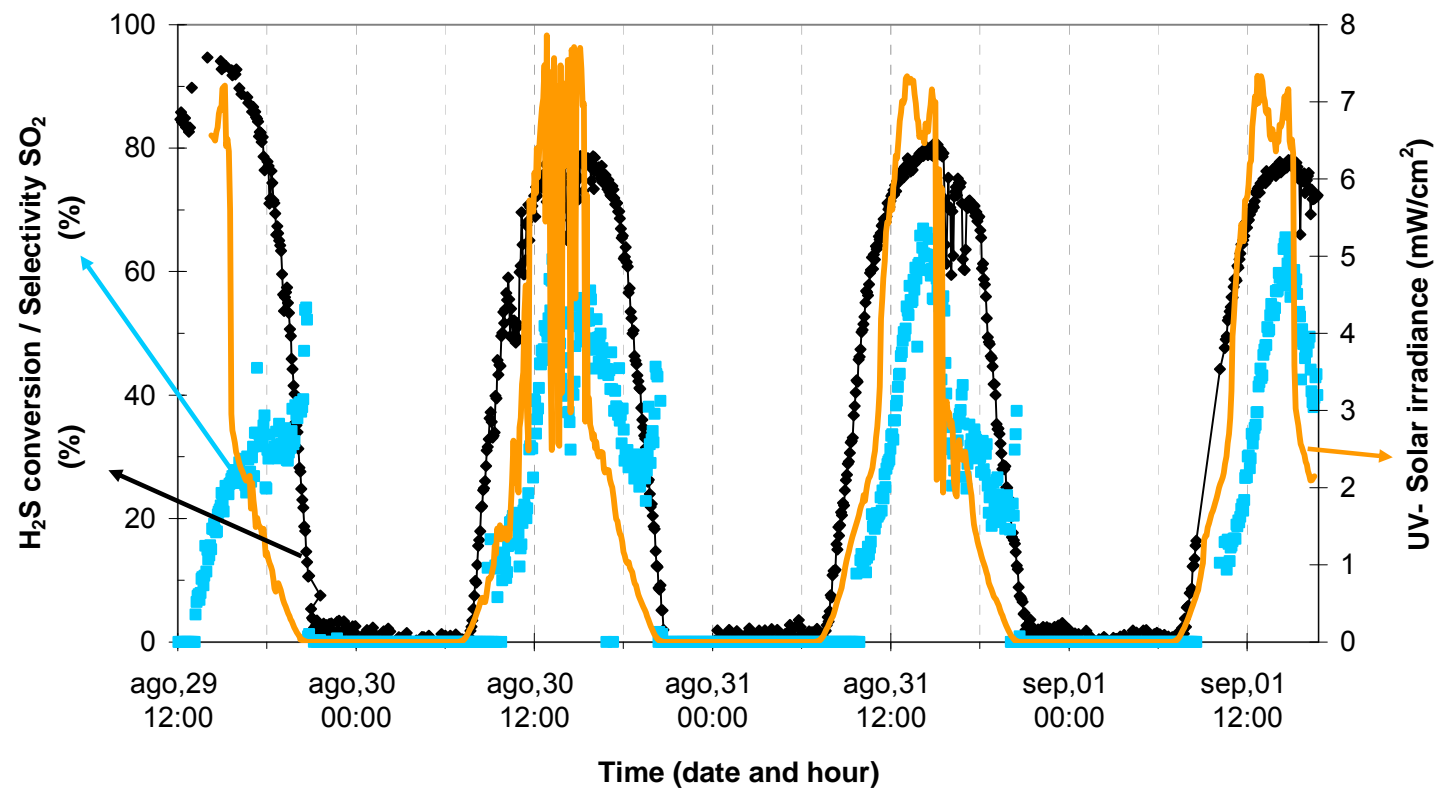

Figure 2. Photocatalytic activity obtained with three photocatalytic PET monoliths at Ciemat. Solar radiation collected with a CPC and UV-irradiance measured on the inner tube.

Operating conditions: $1 \mathrm{~L} \cdot \mathrm{min}^{-1}$ dry air, $15 \mathrm{ppm} \mathrm{H}_{2} \mathrm{~S}, 1 \mathrm{~L}$ reaction volume.

In Figure 3 the conversion and selectivity obtained during the second day of operation are plotted as a function of irradiation. The hysteresis observed, which was repeated in every experimental day, is a result of the difference in adsorption-desorption phenomena between morning and afternoon, as it has been previously observed during solar TCE photocatalytic oxidation [25]. When the sun rises, the temperature increases and the readjustment of the adsorption equilibrium results in enhanced pollutant desorption; consequently the net pollutant elimination efficiency is lower that when the sun goes down, where the contrary effect is observed because the temperature decreases. Selectivity hysteresis was more remarkable than conversion hysteresis during the three consecutive days. This is due to the fact that at night the photocatalyst saturates in $\mathrm{H}_{2} \mathrm{~S}$ while $\mathrm{SO}_{2}$ is desorbed. The higher adsorption of $\mathrm{SO}_{2}$ is responsible for the delay in $\mathrm{SO}_{2}$ appearance in the morning and the high selectivity values observed at sunset, when $\mathrm{SO}_{2}$ is still desorbing despite the absence of photocatalytic activity. 


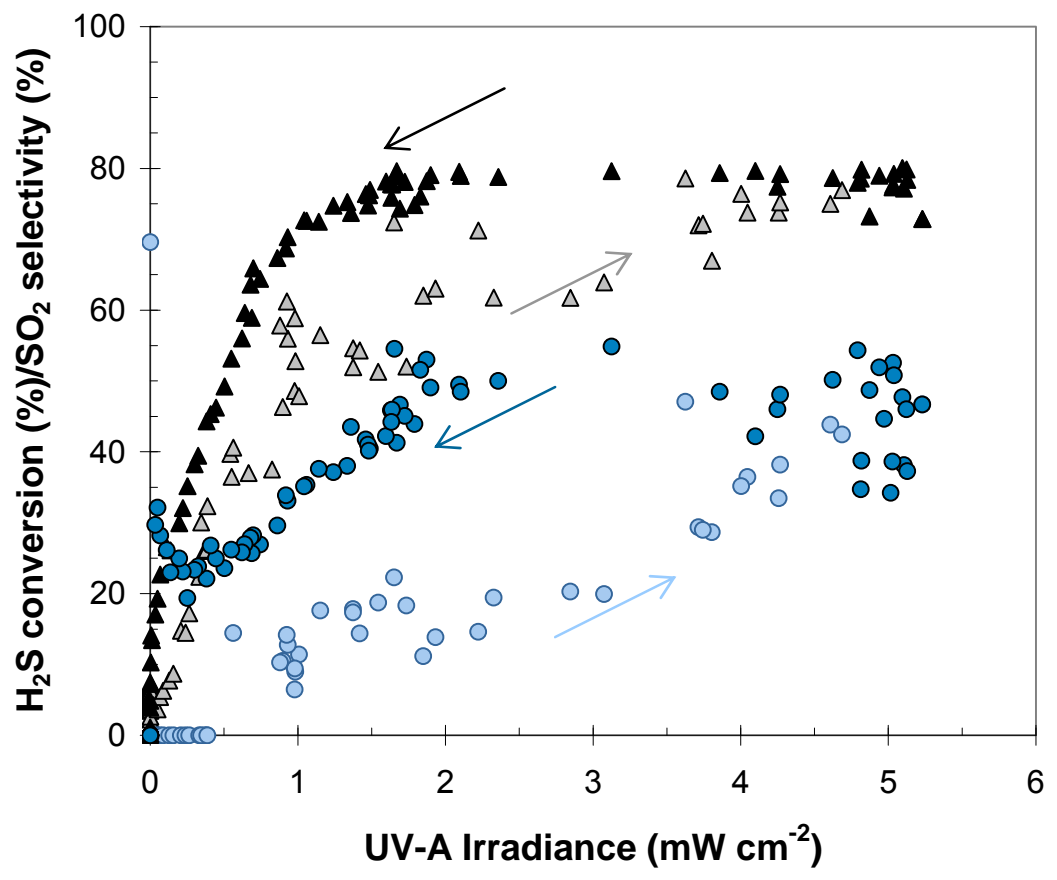

Figure 3. Daily photocatalytic activity cycle (August $\left.30^{\text {th }}\right)$. Conversion ( $\triangle$ morning, $\lambda$ increasing irradiation; $\boldsymbol{\Delta}$ afternoon, $\prec$ decreasing irradiation) and selectivity (○morning, $\lambda$ increasing irradiation; Oafternoon, $\measuredangle$ decreasing irradiation) over incident solar irradiance. Operating conditions: $1 \mathrm{~L} \cdot \mathrm{min}^{-1}$ dry air, $15 \mathrm{ppm} \mathrm{H}_{2} \mathrm{~S}, 1 \mathrm{~L}$ reaction volume.

Figure 4 shows the reaction rate obtained as a function of irradiance. At low irradiation levels the reaction rate increased linearly, while at irradiance values $>1 \mathrm{~mW} \cdot \mathrm{cm}^{-2}$ a power dependence of the reaction rate was observed, according to the literature [42, 43]. At high irradiation levels $\left(>2 \mathrm{~mW} \cdot \mathrm{cm}^{-2}\right.$ in the afternoon, $>4.5 \mathrm{~mW} \cdot \mathrm{cm}^{-2}$ in the morning) the reaction rate was controlled by transport phenomena and independent of the irradiance. The higher reaction rate attained in the afternoon is related to the adsorption effect described before in conversion and selectivity values. 


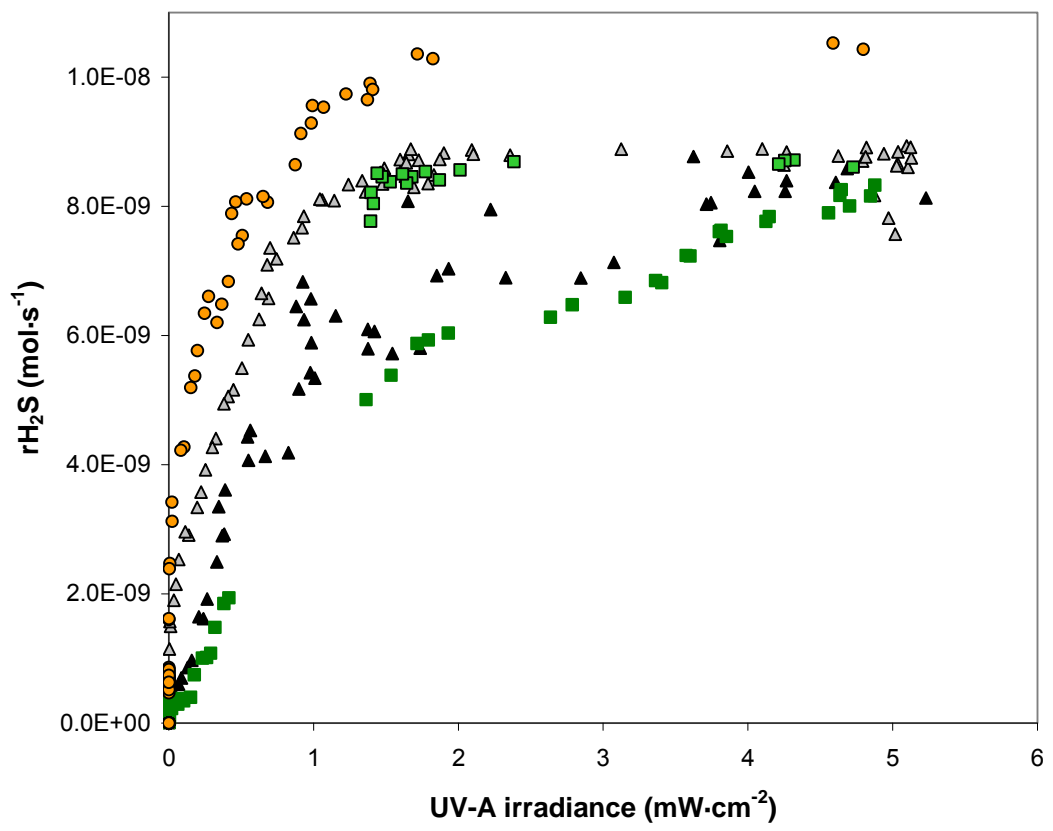

Figure 4. Photocatalytic reaction rate over incident solar irradiance on: August $29^{\text {th }}$ afternoon $(\odot)$; August $30^{\text {th }}$ morning $(\Delta)$ and afternoon $(\Delta)$; September $1^{\text {st }}$ morning $(\square)$ and afternoon $(\square)$. Operating conditions: $1 \mathrm{~L} \cdot \mathrm{min}^{-1}$ dry air, $15 \mathrm{ppm} \mathrm{H}_{2} \mathrm{~S}, 1 \mathrm{~L}$ reaction volume.

The experiment was repeated with $200 \mathrm{ppm} \mathrm{H}_{2} \mathrm{~S}$. In this case low $\mathrm{H}_{2} \mathrm{~S}$ conversion was attained (data not shown). $40 \%$ of the $\mathrm{H}_{2} \mathrm{~S}$ was eliminated during the first day, but fast deactivation by product accumulation occurred due to the dramatic reduction of active sites, a result of the high concentration of pollutant and the absence of humidity. The same fast deactivation was observed in previous experiments performed in dry conditions [37].

A new experiment was performed in March with 14 monoliths filling almost completely the reactor, as shown in Figure 5. A wet $\left(1.1 \% \mathrm{H}_{2} \mathrm{O}_{\mathrm{v}}\right)$ air stream of $3.5 \mathrm{~L} \cdot \mathrm{min}^{-1}\left(12.3 \cdot 10^{-3} \mathrm{~m} \cdot \mathrm{s}^{-1}\right.$ linear velocity) polluted with $30 \mathrm{ppm} \mathrm{H}_{2} \mathrm{~S}$ was treated under complementary solar and artificial radiation. 


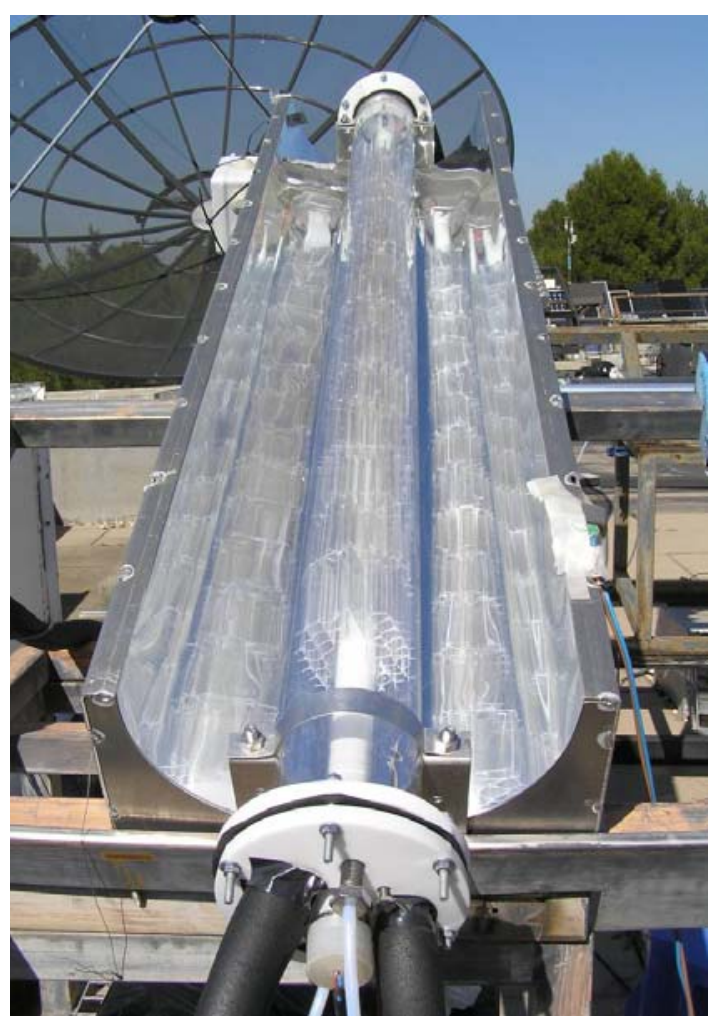

Figure 5. Photograph of the tubular photoreactor during operation with 14 photocatalytic PET monoliths at Ciemat.

Despite the low winter irradiance values and the higher $\mathrm{H}_{2} \mathrm{~S}$ molar flow rate, total $\mathrm{H}_{2} \mathrm{~S}$ elimination was achieved during the day and at night (Figure 6A) and therefore the adequate performance of the photocatalytic reactor under both solar and artificial irradiation was demonstrated. Nevertheless, to the already commented deactivation effect, observed in the second day of operation, the photocatalytic activity decayed in the early morning and was recovered at sunrise. One of the main causes to which this process can be ascribed is the low temperature reached at night (Figure $6 \mathrm{~B}$ ), which strongly affected the lamp output and consequently caused a detrimental effect on the photocatalytic activity. The optimal performance of fluorescent lamps is typically obtained at $25^{\circ} \mathrm{C}$ ambient temperature for T8/T26 fluorescents $[44,45]$. At $5^{\circ} \mathrm{C}$ the theoretical lamp output should be $60 \%$ and the recommended temperature for the electronic ballast is above $10^{\circ} \mathrm{C}$. Moreover, dew and water condensation produced inside the reactor could pose an additional problem. During the experiments, the lamp irradiance changed from $6 \mathrm{~mW} \cdot \mathrm{cm}^{-2}$, at laboratory conditions $\left(25^{\circ} \mathrm{C}\right)$, to values below $2 \mathrm{~mW} \cdot \mathrm{cm}^{-}$ ${ }^{2}$, obtained outdoors in the early morning $\left(5^{\circ} \mathrm{C}\right)$, accompanied by "fluttering". This represents a $66 \%$ reduction of the radiation intensity. This effect must be taken into account for outdoors applications. "Cold weather" fluorescent lamps and ballasts, better isolation or alternative radiation sources, such as UV Light Emitting Diods (LEDs), whose performance is enhanced at low temperatures, could improve the photocatalytic efficiency in cold seasons and/or locations. 

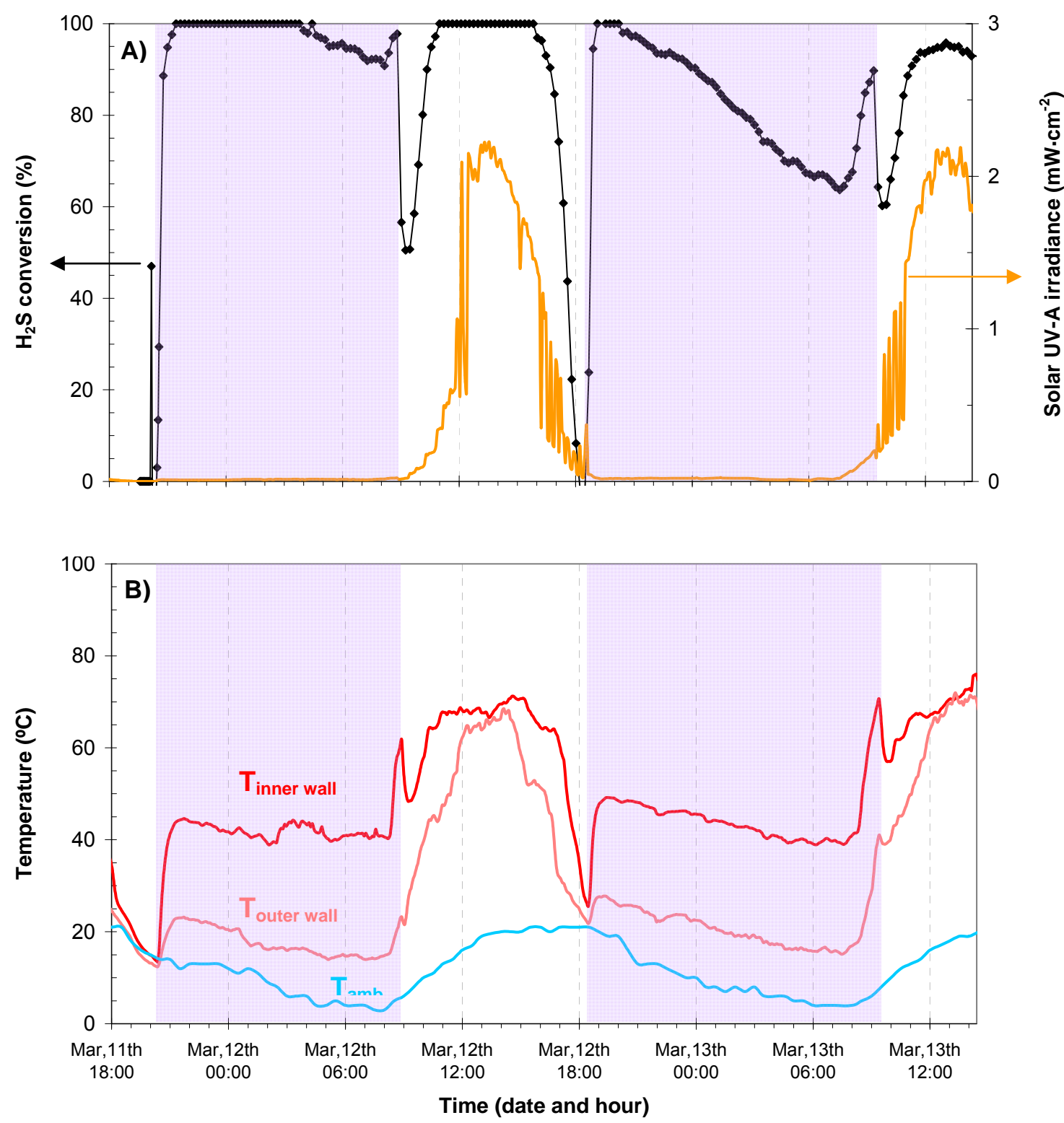

Figure 6. Operating conditions: $3.5 \mathrm{~L} \cdot \mathrm{min}^{-1}, 1.1 \% \mathrm{H}_{2} \mathrm{O}_{\mathrm{v}}, 15 \mathrm{ppm} \mathrm{H}_{2} \mathrm{~S}, 4.6 \mathrm{~L}$ reaction volume. The inner UV-lamp is available for irradiation at night (shaded area). A) $\mathrm{H}_{2} \mathrm{~S}$ conversion (black) obtained with 14 photocatalytic PET monoliths. Solar UV radiation (orange) is collected with a CPC and measured on the CPC aperture plane. B) Ambient temperature (blue) and temperature measured inside the reactor on the inner (red) and outer (pink) walls.

\subsection{Configuration B: Monolith-like units composed by glass plates}

An alternative configuration consisted in the use of star-shaped structures [40] -especially designed for distribution of flat-shaped catalysts in tubular photoreactors- to build monolith-like units with coated glass plates. The photocatalyst had been previously tested in a small flat reactor for the abatement of TCE and $\mathrm{H}_{2} \mathrm{~S}$ [46]. In this work, two tests were performed with the new photoreactor under sun irradiation, both in the same operating conditions: $0.850 \mathrm{~L} \cdot \mathrm{min}^{-1}$ (3.10 $0^{-3} \mathrm{~m} \cdot \mathrm{s}^{-1}$ linear velocity), $1.1 \% \mathrm{H}_{2} \mathrm{O}_{\mathrm{v}}, 25 \mathrm{ppm} \mathrm{H}_{2} \mathrm{~S}$ (Figure 7). For the first test, three 
monolith-like structures were employed and almost total $\mathrm{H}_{2} \mathrm{~S}$ conversion was achieved, although it decayed from $96.4 \%$ to $84.9 \%$ (reaction rate from $1.5 \cdot 10^{-8}$ to $1.3 \cdot 10^{-8} \mathrm{~mol} \cdot \mathrm{s}^{-1}$ ) in three days. In a new test with 10 monoliths, the elimination of $\mathrm{H}_{2} \mathrm{~S}$ was complete during the 10 days of operation. In both cases and according to previous results increasing amounts of $\mathrm{SO}_{2}$ were present in the outlet (data not shown).
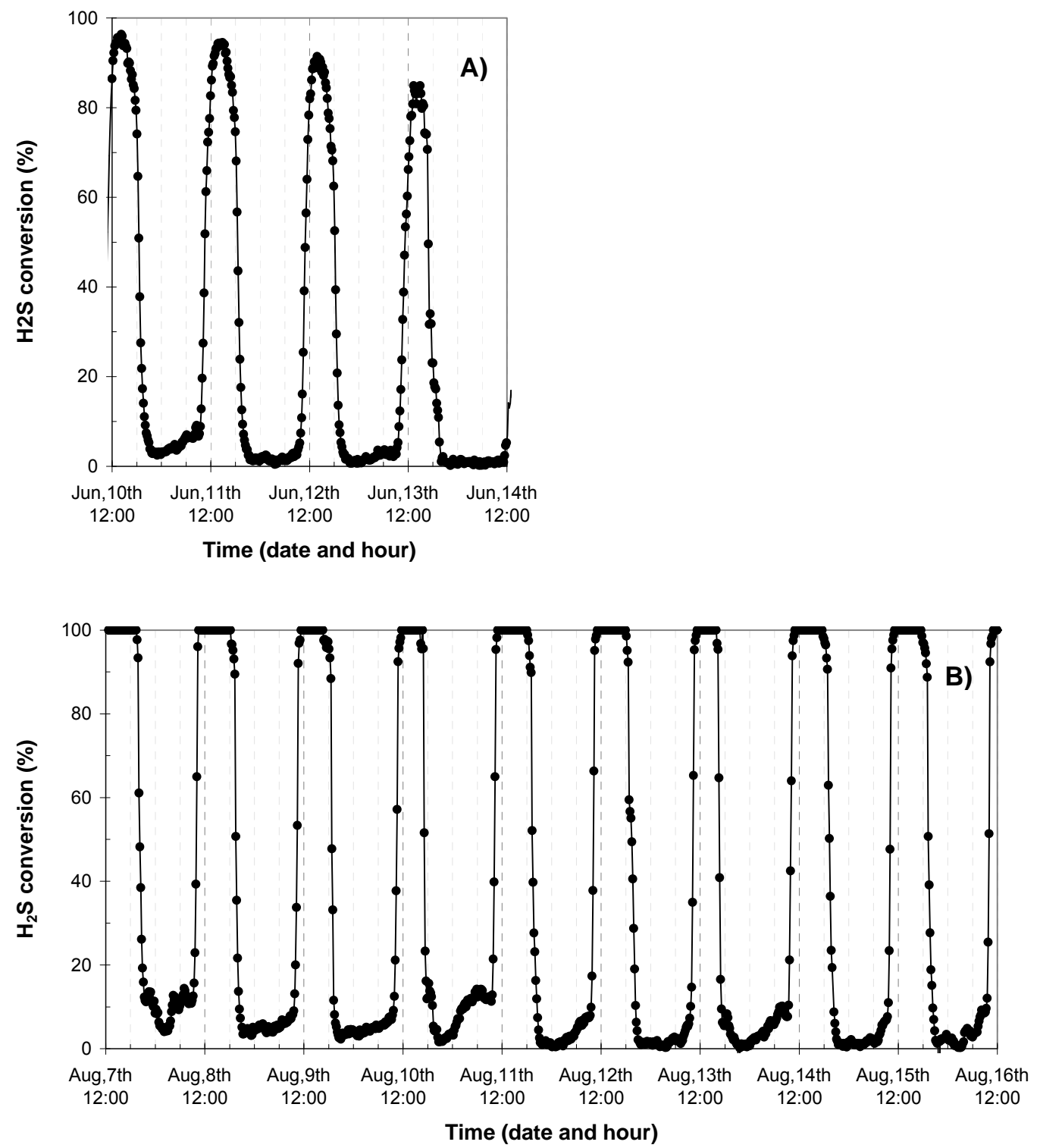

Figure 7. $\mathrm{H}_{2} \mathrm{~S}$ conversion obtained with solar irradiation in the laboratory during the first use of monolith-like structures composed by 8 glass slides each. Operating conditions: $0.850 \mathrm{~L} \cdot \mathrm{min}^{-1}$, $1.1 \% \mathrm{H}_{2} \mathrm{O}_{\mathrm{v}}, 25 \mathrm{ppm} \mathrm{H}_{2} \mathrm{~S}$. A) Three monolithic structures (1 $\mathrm{L}$ reaction volume), B) Ten monolithic structures (3.6 $\mathrm{L}$ reaction volume).

The tubular photoreactor was tested with configuration B at semi-pilot plant scale in a WWTP located in Madrid (Spain). Three units composed by 8 glass slides each were mounted and tested. Initially, three consecutive tests were performed in the laboratory with artificial irradiation, in order to study the regeneration of the photocatalytic properties by washing the photocatalyst 
after each use. The photocatalytic activity of the monoliths in the first and third uses is shown in Figure 8.

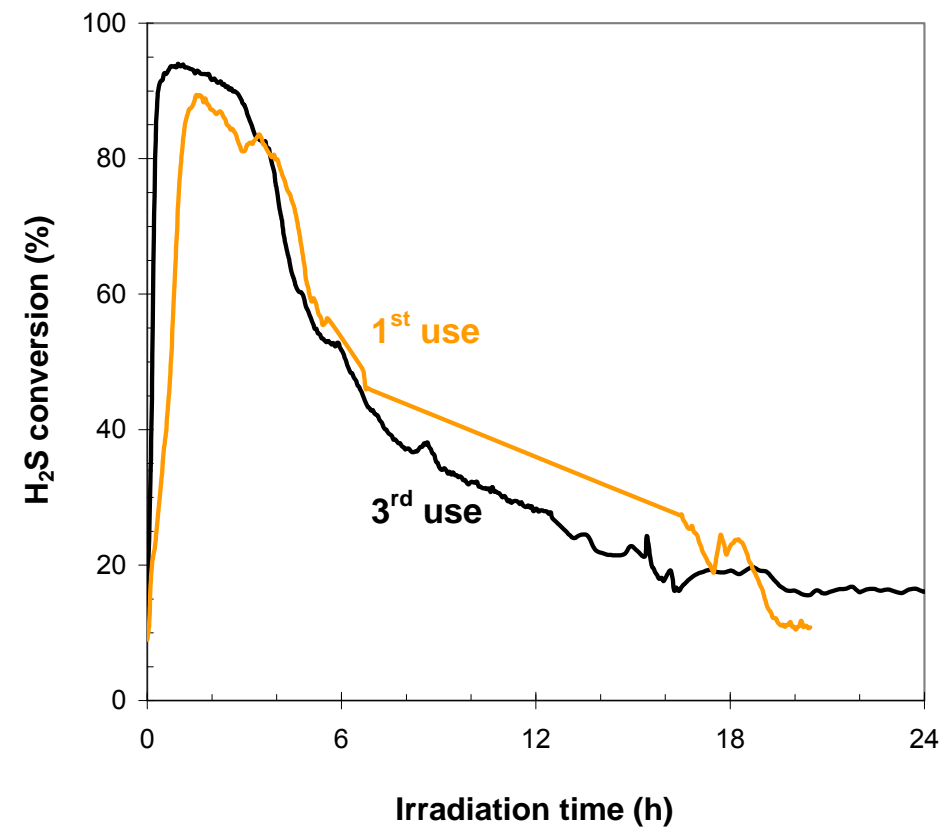

Figure 8. $\mathrm{H}_{2} \mathrm{~S}$ elimination during the treatment of $1 \mathrm{~L} \cdot \mathrm{min}^{-1}$ wet air $\left(1.1 \% \mathrm{H}_{2} \mathrm{O}_{\mathrm{v}}\right)$ with $35 \mathrm{ppm} \mathrm{H}_{2} \mathrm{~S}$ under artificial irradiation in the laboratory. First use (orange) and third use (black) of three monolith-like structures composed by 8 glass slides.

The deactivation was faster than when only solar radiation was employed, due to the continuous operation of the reactor. It can be observed that the activity of the catalyst was regenerated with the washing procedure, according to previous results $[5,41]$. Table 1 summarizes the analysis of the distilled water used to wash the catalyst after the first use. No Ti was detected and most of the sulfate removed was collected in the first rinse, which indicates the resistance of the coating and the weakness of the adsorption species.

Table 1. Analysis of wash water of three of the glass slides after first use in the laboratory.

\begin{tabular}{|c|c|cc|}
\hline Sample & Rinse & $\begin{array}{c}\mathrm{Ti} \\
\mathrm{mg} \cdot \mathrm{L}^{-1}\end{array}$ & $\begin{array}{c}\mathbf{S O}^{\mathbf{}^{2-}} \\
\mathrm{mg} \cdot \mathrm{L}^{-1}\end{array}$ \\
\hline \multirow{2}{*}{$\mathbf{1}$} & $\mathbf{1}^{\text {st }}$ & $<0.03$ & 2.3 \\
\cline { 2 - 4 } & $\mathbf{2}^{\text {nd }}$ & $<0.03$ & 0.1 \\
\hline \multirow{2}{*}{2} & $\mathbf{1}^{\text {st }}$ & $<0.03$ & 2.3 \\
\cline { 2 - 4 } & $\mathbf{2}^{\text {nd }}$ & $<0.03$ & 0.1 \\
\hline \multirow{2}{*}{3} & $\mathbf{1}^{\text {st }}$ & $<0.03$ & 2.2 \\
\cline { 2 - 4 } & $\mathbf{2}^{\text {nd }}$ & $<0.03$ & 0.1 \\
\hline
\end{tabular}

After the third use, the three units were washed again and tested in February in the semi-pilot plant located in a WWTP in Madrid. $1 \mathrm{~L} \cdot \mathrm{min}^{-1}$ air coming from the primary sludge tank was circulated through the photocatalytic reactor, and the concentration of $\mathrm{H}_{2} \mathrm{~S}$ and $\mathrm{SO}_{2}$ was monitored before and after the photocatalytic treatment. As it can be observed in Figure 9, the photocatalytic treatment successfully removed most of the $\mathrm{H}_{2} \mathrm{~S}$ of the air stream (Figure $9 \mathrm{~A}$ ). 
However, as it was expected, the activity decayed with time and $\mathrm{SO}_{2}$ was released in the outlet gas stream. It is worth noting that the photocatalytic treatment was also effective against many other VOCs that were present in the air (Figure 9, B).
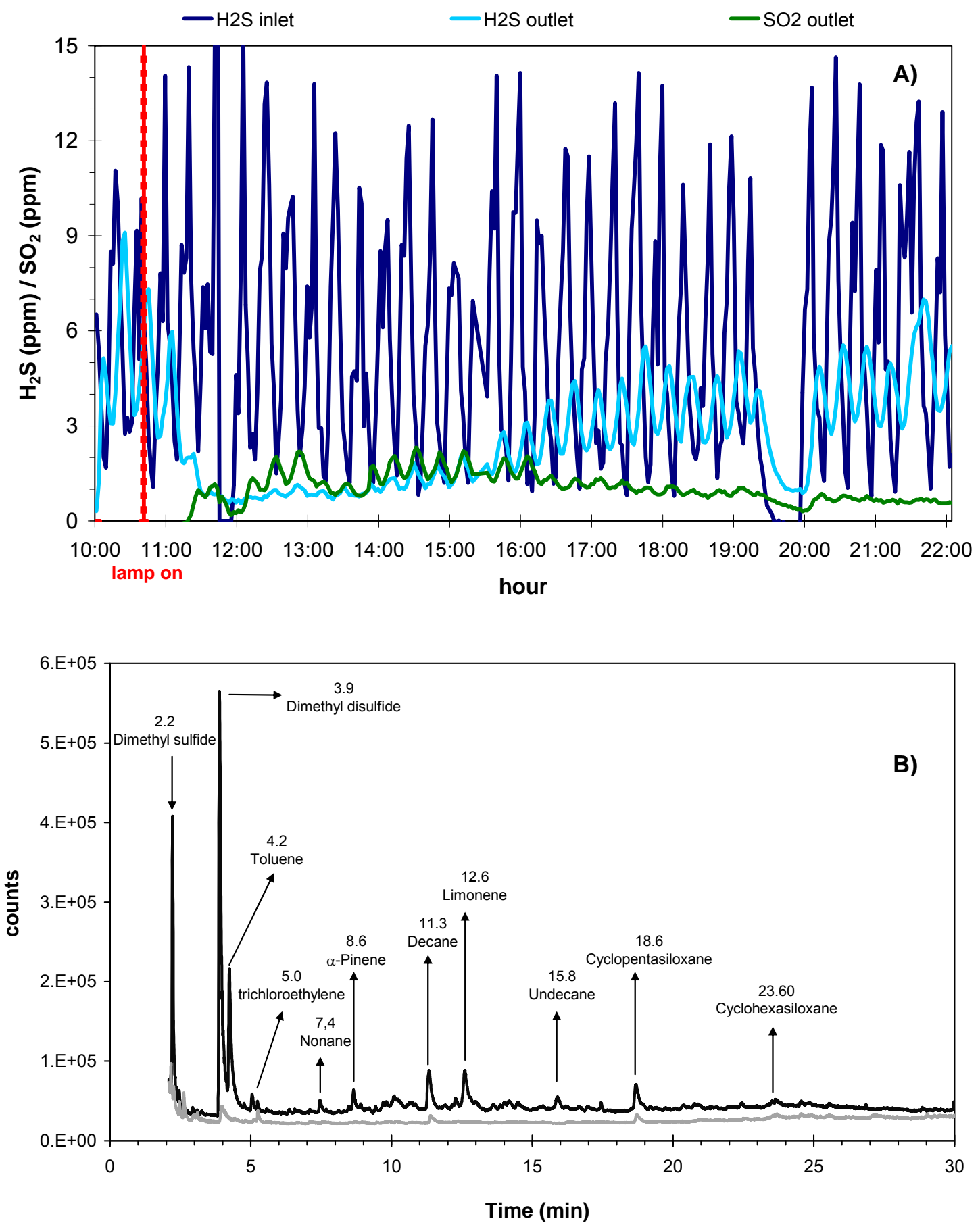

Figure 9. Treatment of $1 \mathrm{~L} \cdot \mathrm{min}^{-1}$ real air in a WWTP with artificial irradiation. Fourth use of three monolith-like structures, after three uses and regenerations in the laboratory. A) $\mathrm{H}_{2} \mathrm{~S}$ elimination and $\mathrm{SO}_{2}$ formation over time. B) Other VOCs detected in the inlet (black) and outlet (grey) by ATD-GC-MS.

Besides $\mathrm{H}_{2} \mathrm{~S}$, the main pollutants found in the air of the wastewater treatment plant were organic sulfides, aromatic compounds -such as toluene, benzene or xylene-, heterocyclic compounds, 
aliphatic hydrocarbons and terpenes. The concentration of most of these compounds decreased drastically with the photocatalytic treatment and conversion values above $90 \%$ were attained in most of the cases.

\section{CONCLUSIONS}

A prototype of photocatalytic versatile reactor consisting on a vertical, south-oriented, borosilicate glass tubular reactor with a CPC-type collector and an inner lamp is proposed. The new tubular reactor may operate 24 hours a day using both types of radiation, solar and artificial, although low temperatures, below $5^{\circ} \mathrm{C}$, strongly affect the performance of fluorescent lamps.

Different types of supported photocatalysts may be employed. UV-A transparent photocatalysts allow an efficient use of the activation energy by irradiation in one single direction of more than one photoactive surface. The adequate distribution of an easy to handle photocatalyst inside the tubular reactor can be achieved using as support PET monoliths and monolith-like units composed by flat plates. Both configurations are cheap, low-volume and open structures that facilitate the air flow. The appropriate catalyst distribution, together with the use of a solar collector, reduces the energy input. High capacity and flexibility of operation are assured with the modularity of the design, since the number of monolithic structures inside the reactor and the number of parallel operating reactors can be easily modified.

The efficiency of the photocatalytic system with either solar or artificial radiation to oxidize the $\mathrm{H}_{2} \mathrm{~S}$ contained in an air stream was demonstrated in the laboratory and for the real air of a wastewater treatment plant located in Madrid (Spain). Although the deactivation of the catalyst occurred, the regeneration of the exhausted photocatalyst was achieved by washing with water. The regeneration can be performed extracting the photocatalyst or introducing the water inside the reactor by one of the inlets. If parallel reactors are used, a semi-continuous operation that includes deactivation-regeneration cycles is possible.

$\mathrm{SO}_{2}$ liberation during $\mathrm{H}_{2} \mathrm{~S}$ photocatalytic oxidation needs to be avoided, for example by coupling this technology with an adsorption unit. A promising solution to avoid the undesired subsequent adsorption unit may be the use of hybrid adsorbents/photocatalysts [41]. An interesting alternative is now opened with the use of the star-shaped structures that allow opaque materials conformed as plates to be employed with fairly good irradiation of the active surface [47].

\section{ACKNOWLEDGMENTS}

The authors would like to acknowledge Comunidad de Madrid (DETOX- $\mathrm{H}_{2} \mathrm{~S}$ S0505/AMB/0406), Ministerio de Ciencia e Innovación (CTM2008-06876-C02-01) and AECID for financial support and Gloria Simón Naranjo and Francisco Sánchez Moreno for the help with the reactor set-up. 
[1] P. Fernández-Ibáñez, J. Blanco, S. Malato, F.J. Nieves, Water Res. 37 (2003) 31803188.

[2] F. Chen, J. Zhao, Catal. Lett. 58 (1999) 245-247.

[3] D.F. Ollis, Ann. N. Y. Acad. Sci. 984 (2003) 65-84.

[4] A. Sirisuk, C.G. Hill Jr., M.A. Anderson, Catal. Today 54 (1999) 159-164.

[5] R. Portela, B. Sanchez, J.M. Coronado, R. Candal, S. Suarez, Catal. Today 129 (2007) 223-230.

[6] E.R. Bandala, C.A. Arancibia-Bulnes, S.L. Orozco, C.A. Estrada, Solar Energy 77 (2004) 503-512.

[7] D. Bockelmann, R. Goslich, D. Bahnemann, D. Weichgrebe, Sol. Energy Mater. Sol. Cells 38 (1995) 441-451.

[8] J. Blanco, S. Malato, P. Fernandez, A. Vidal, A. Morales, P. Trincado, J.C. Oliveira, C. Minero, M. Musci, C. Casalle, M. Brunotte, S. Tratzky, N. Dischinger, K.-H. Funken, C. Sattler, M. Vincent, M. Collares-Pereira, J.F. Mendes, C.M. Rangel, Solar Energy 67 (1999) 317-330.

[9] J. Pacheco, A.S. Watt, C.S. Turchi, Jint Solar Engineering Conference ASME (1993) 43-49.

[10] D. Bahnemann, Solar Energy 77 (2004) 445-459.

[11] S. Malato, J. Blanco, M.I. Maldonado, P. Fernandez, W. Gernjak, I. Oller, Chemosphere 58 (2005) 391-398.

[12] I. Munoz, J. Peral, J. Antonio Ayllon, S. Malato, P. Passarinho, X. Domenech, Water Res. 40 (2006) 3533-3540.

[13] M.E. Zorn, S.O. Hay, M.A. Anderson, Appl. Catal. B 99 (2010) 420-427.

[14] M.M. Ballari, M. Hunger, G. Hüsken, H.J.H. Brouwers, Appl. Catal. B 95 (2010) 245254.

[15] J. Taranto, D. Frochot, P. Pichat, Sep. Purif. Technol. 67 (2009) 187-193.

[16] L.A. Dibble, G.B. Raupp, Environ. Sci. Technol. 26 (1992) 492-495.

[17] A.V. Vorontsov, E.E. Savinov, P.G. Smirniotis, Chem. Eng. Sci. 55 (2000) 5089-5098.

[18] W. Nam, J. Kim, G. Han, Chemosphere 47 (2002) 1019-1024.

[19] H.d. Lasa, B. Serrano, M. Salaices, Photocatalytic Reaction Engineering, Springer, New York, 2005.

[20] H.W. Read, X. Fu, L.A. Clark, M.A. Anderson, T. Jarosch, Soil and Sediment Contamination 5 (1996) 187-202.

[21] P. Pichat, J. Disdier, C. Hoang-Van, D. Mas, G. Goutailler, C. Gaysse, Catal. Today 63 (2000) 363-369.

[22] A. Watt, K. Magrini, L.E. Carlson, E.J. Wolfrum, S.A. Larson, C. Roth, G.C. Glatzmaier, J.Air Waste Manage.Assoc. 49 (1999) 1368-1373.

[23] W.H. Ching, M. Leung, D.Y.C. Leung, Solar Energy 77 (2004) 129-135. 
[24] J.M. Coronado, B. Sánchez, F. Fresno, S. Suárez, R. Portela, J.Solar Energy Eng. 130 (2008) 041012 (041015 pages)

[25] S. Suárez, T.L.R. Hewer, R. Portela, M.D. Hernandez-Alonso, R.S. Freire, B. Sanchez, Appl. Catal. B 101 (2011) 176-182.

[26] S. Irandoust, B. Andersson, Catal. Rev. - Sci. Eng. 30 (1988) 341-392.

[27] M.L. Sauer, D.F. Ollis, J. Catal. 149 (1994) 81-91.

[28] J. Blanco, P. Avila, A. Bahamonde, E. Alvarez, B. Sánchez, M. Romero, Catal. Today 29 (1996) 437-442.

[29] K. Suzuki, in: D.F.Ollis, H.Al-Ekabi (Eds.), Photocatalytic Purification and Treatment of Water and Air, Elsevier Science Publishers B.V., 1993, pp. 421-434.

[30] M. Hossain, G.B. Raupp, Chem. Eng. Sci. 54 (1999) 3027-3034.

[31] G.B. Raupp, A. Alexiadis, M.M. Hossain, R. Changrani, Catal. Today 69 (2001) 41-49.

[32] J.T. Carneiro, R. Berger, J.A. Moulijn, G. Mul, Catal. Today 147 (2009) S324-S329.

[33] A.V. Vorontsov, E.N. Savinov, G.B. Barannik, V.N. Parmon, V.N. Troitsky, Catal. Today 39:3 (1997) 207-218.

[34] G.E. Imoberdorf, A.E. Cassano, H.A. Irazoqui, O.M. Alfano, Catal. Today 129 (2007) 118-126.

[35] M.D. Hernández-Alonso, I. Tejedor-Tejedor, J.M. Coronado, J. Soria, M.A. Anderson, Thin Solid Films 502 (2006) 125-131.

[36] B. Sánchez, A.I. Cardona, M. Romero, P. Avila, A. Bahamonde, Catal. Today 54 (1999) 369-377.

[37] R. Portela, B. Sánchez, J.M. Coronado, J. Adv. Oxid. Technol. 10 (2007) 375-380.

[38] B. Sánchez, J.M. Coronado, R. Candal, R. Portela, I. Tejedor, M.A. Anderson, D. Tompkins, T. Lee, Appl. Catal. B 66 (2006) 295-301.

[39] R. Portela, Eliminación fotocatalítica de $\mathrm{H}_{2} \mathrm{~S}$ en aire mediante $\mathrm{TiO}_{2}$ soportado sobre sustratos transparentes en el UV-A, Madrid, 2009.

[40] B. Sánchez, R. Portela, S. Suárez, J.M. Coronado, Fotorreactor tubular para fotocatalizadores soportados (Tubular photoreactor for supported photocatalysts). PCT/ES2010/070799, Spain, 2009.

[41] R. Portela, S. Suárez, S.B. Rasmussen, N. Arconada, Y. Castro, A. Durán, P. Ávila, J.M. Coronado, B. Sánchez, Catal. Today 151 (2010) 64-70.

[42] T.N. Obee, S.O. Hay, Environ.Sci.Technol. 31 (1997) 2034-2038.

[43] M.R. Hoffmann, S.T. Martin, W.Y. Choi, D.W. Bahnemann, Chem. Rev. 95 (1995) 6996.

[44] T.M. Chung, C.H. Yip, Architectural Science Review 50 (2007) 77-82.

[45] J.V. Broekhoven, in: R. Kane, H. Sell (Eds.), Revolution in lamps: a chronicle of 50 years of progress (2nd ed.), The Fairmont Press, Inc, Lilburn, Georgia, 2001.

[46] J.M. Coronado, S. Suárez, R. Portela, B. Sánchez, J. Adv. Oxid. Technol. 11 (2008) 362-369(368). 
[47] R. Portela, R.F. Tessinari, S. Suárez, S.B. Rasmussen, M.C. Canela, P. Avila, B. Sánchez, (Under preparation). 